\title{
CrimRxiv
}

\section{Policing Mental Health: The Composition and Perceived Challenges of Co-Response Teams and Crisis Intervention Teams in the Canadian Context}

Jacek Koziarski ${ }^{1}$, Christopher O'Connor ${ }^{2}$, Tyler Frederick ${ }^{2}$

${ }^{1}$ University of Western Ontario, ${ }^{2}$ University of Ontario Institute of Technology

Published on: Jul 03, 2020

DOI: $10.21428 / c b 6 a b 371.032 b 351 b$

License: Creative Commons Attribution 4.0 International License (CC-BY 4.0). 


\section{ABSTRACT:}

Due to an increase in interactions between the police and persons with perceived mental illness (PwPMI), police services have begun deploying specialized crisis responses to more adequately address these calls. One such response is a Crisis Intervention Team (CIT) that is comprised of frontline officers who are specially trained on mental health; another is a Co-Response Team (CRT) where an officer is paired with a mental health practitioner. With police services presumably shifting scarce resources to deploy these responses, it is paramount to understand the challenges they may endure. With little Canadian research on these responses to-date, the purpose of this paper is to document which Canadian police services deploy these responses and how their composition varies by jurisdiction, as well as their perceived challenges. Through a mixed methodological approach, the results indicate that most of the participating services deploy varying compositions of a CIT and/or CRT, but are perceived to endure a variety of challenges which may impede the overall success of these responses. A call for future research is made which may assist Canadian police services in addressing some of the identified challenges.

Keywords: Policing; Mental Health; Persons with Perceived Mental Illness (PwPMI); Co-Response Team (CRT); Crisis Intervention Team (CIT)

Corresponding Author: Jacek Koziarski - jkoziars@uwo.ca

This is a pre-copyedited, author-produced version of an article accepted for publication in Police Practice \& Research, following peer review. The version of record, Koziarski, J., O'Connor, C., \& Frederick, T. (2021). Policing Mental Health: The Composition and Perceived Challenges of Co-Response Teams and Crisis Intervention Teams in the Canadian Context. Police Practice \& Research, is available online at: https://doi.org/10.1080/15614263.2020.1786689. When citing, please cite the version of record.

\section{Introduction}

In Canada, the most recent estimates suggest that there are approximately 6.7 million individuals - or $19.8 \%$ of the entire population - living with mental illness, and that by the year 2041, that estimate is expected to increase to approximately 8.9 million (Smetanin, Stiff, Briante, Adair, Ahmad, and Khan 2011). While not all individuals who live with a mental illness come into contact with the police, interactions with persons 
with perceived mental illness (PwPMI) 1 have been increasing in Canada (Durbin, Lin, and Zaslavska, 2010a; Vaughan and Andresen 2018), with estimates suggesting that PwPMI comprise up to 15\% of yearly calls for service (Cotton and Coleman 2008; see also Crocker, Hartford, and Heslop 2009; Boyce, Rotenberg and Karam 2015).

In response, efforts have been made to develop frontline mental health training standards and curriculums to better prepare and equip officers for PwPMI interactions (Cotton and Coleman 2008; Coleman and Cotton 2010a). Additionally, police services in Canada, and elsewhere, have turned their attention towards implementing specialized responses to PwPMI - such as Crisis Intervention Teams (CITs) and CoResponse Teams (CRTs) - which further seek to improve police-PwPMI interactions. The former is comprised of frontline officers who are specially trained on mental health and mental health-related issues, whereas the latter is typically comprised of a specially trained officer who is paired with a mental health practitioner or on-call practitioners who attend PwPMI calls at the request of frontline officers (Dupont, Cochran, and Pillsbury, 2007; Iacobucci 2014).

The limited research on these responses to-date has generated promising evidence with respect to decreasing the criminalization of PwPMI, improving officer knowledge and training on mental health, generating more positive interactions, and generating stronger police partnerships with the mental health system, among other objectives (Bird and Shemilt 2019; Shapiro et al. 2015; Taheri 2016; Watson, Compton, and Draine 2017; Dewa et al. 2018; Puntis et al. 2018). However, the literature also suggests that these responses endure through a multitude of challenges, such as long hospital wait times before a PwPMI is transferred to hospital care, low staffing, low training budgets, and a lack of 24/7 deployment, all of which lead to an inability of CITs and CRTs to attend PwPMI calls (Iacobucci 2014; Skubby et al. 2013; Steadman, Deane, Borum, and Morrissey 2000).

In the Canadian context, there is a significant lack of empirical research on CITs and CRTs. More specifically, is not clear where and how these responses are being implemented and what kind of differences exist. Furthermore, with costs related to PwPMI calls increasing in tandem with PwPMI-related CFS (Vaughan and Andresen 2018), and police services presumably shifting their limited resources to deploy CITs/CRTs, it is important to understand what challenges they face from the perspective of Canadian police officers involved in their deployment. Any endured challenges ultimately have the potential to limit the effectiveness of these responses $\underline{2}$. As such, this paper seeks to gather additional information on CITs and CRTs in Canada, 
with a primary focus on documenting which Canadian police services deploy these responses and how they are composed, as well as the perceived challenges experienced by these responses.

\section{Literature Review}

\section{Brief Overview of Police-PwPMI Interactions}

Historically, reported police contacts with PwPMI were rare in the pre-

deinstitutionalization era (Ellis 2014; Engel and Silver 2001); however, postdeinstitutionalization, police contacts with PwPMI are growing, which is largely being attributed to a significant lack of mental health resources (Cotton 2004; Cotton and Coleman 2010; Forchuk, Jensen, Martin, Csiernik, and Atyeo 2010; Lamb and Bachrach 2001). In the Canadian context specifically, it is estimated that between $5 \%$ (Brink et al. 2011) and 15\% of all police calls involve a PwPMI - a population who are two-to-three times more likely to have an interaction with police than the general population (Cotton and Coleman 2008). Crocker at al. (2009) found that in a sample of 767,365 police interactions, PwPMI represented only $0.9 \%$ of the sample, but $6.2 \%$ of all interactions; whereas Boyce et al. (2015) found that in a sample of 5 million police contacts in Canada, 18.8\% were PwPMI. Furthermore, research also suggests that PwPMI interactions are increasing in terms of frequency and cost. More specifically, Vaughan and Andresen (2018) found that not only were CFS increasing yearly by 9.70\% for select services in British Columbia (BC), but also that the cost of attending these calls increased by an average of $13.56 \%$ per year.

Furthermore, police-PwPMI interactions may take approximately 20 minutes longer than non-PwPMI interactions (Schulenberg 2016) and can last up to several hours in some circumstances (Wells and Schafer 2006). However, the contexts in which police may come into contact with PwPMI vary greatly. These include social support, informal interactions, disturbances, and mental health crises, among others (Coleman and Cotton 2010b). Certain interactions can also be made more challenging through additional situational factors. Substance use, for example, is present in approximately 25-30\% of PwPMI calls (Charette, Crocker, and Billette 2011; Shore and Lavoie 2018), and it can have a significant impact on how the police approach a call they perceive as being PwPMI-related (Bohrman, Wilson, Watson, and Draine 2018).

Ultimately, in light of increasing PwPMI interactions, police officers have been labeled as 'psychiatrists in blue' (Menzies 1987), 'street-corner psychiatrists' (Iacobucci 2014), and 'de-facto mental health professionals' (Compton et al. 2014a) for assuming a role 
traditionally held by nurses and social workers (Ellis 2014). Iacobucci (2014:96) argues that the police have had to fulfill these labels by default to the point where it has become a "regular part of an officer's job." While some officers have accepted this new role (Girard et al. 2014; Watson, Corrigan, and Ottati 2004), some findings suggest there is a belief within police culture that interactions with PwPMI is 'not real police work' (Coleman and Cotton 2010b; Schulenberg 2016). For example, Schulenberg (2016) found a disjuncture between department policy and police culture which may impact the ability of officers to address PwPMI appropriately. This is because the former encourages diversion, whereas the latter can pressure officers to resolve encounters rapidly and informally - consuming 3.2 times less time than hospitalization (Charette et al. 2011) - with an added encouragement of charges and citations (Schulenberg 2016). Relatedly, findings indicate that PwPMI are four times more likely to be arrested than non-PwPMI (Boyce et al. 2015), particularly for nuisance and order-related crimes (Schulenberg 2016). Some, however, argue that even though there is a disproportionality in arrests, it does not mean that they are not justified (Engel and Silver 2001).

Moreover, though use of force is found to be used in less than $1 \%$ of all police interactions (Adams 2004), findings also indicate that PwPMI are more likely to have force used against them (Morabito, Socia, Wilk, and Fisher 2017). Livingston et al. (2014), for example, report that over half of the participants in their study had some level of force used against them. Some reported being handcuffed and/or physically restrained by officers; whereas others reported being pushed, punched, kicked, or having a weapon used against them (e.g., baton, Taser, firearm) (Livingston et al. 2014). In extremely rare instances, interactions have led to the death of a PwPMI. Canadian incidents, such as those including Lester Donaldson, Sammy Yatim, Michael MacIssac, and others, have ignited numerous reports and inquests into police use of force and police responses to PwPMI more generally, with a particular focus on the need for enhanced training and more sophisticated responses to PwPMI (Hall 2014; Iacobucci 2014; Dube 2016; McNeilly 2017).

Although research suggests that PwPMI may disproportionally endure unnecessary arrest, force, or even death, many participants of various studies rated their experiences with police as fairly positive (see Brink et al. 2011; Desmarais et al. 2014; Livingston et al. 2014). For example, one individual interviewed by Brink et al. (2011:44) explained that, "sometimes cops are kind and helpful; other ones can be cocky and overly aggressive, but, I guess, overall, it's a healthy balance." Additionally, in instances when some participants had a negative contact with police, some tended 
to target the individual officer as the source of the negative contact, as opposed to the police institution as a whole (Brink et al. 2011). Overwhelmingly, however, the individuals in these studies suggested that officers need more training with respect to mental illness.

In Canada, mental health training for police officers is conducted at two levels: at one of 13 police colleges for new hires and in-service training. The most up-to-date information suggests that training at police colleges for mental health is conducted as a stand-alone module, or combined with other forms of training (e.g., tactical communication). The length of training varies by police college - from one to 20 hours - which can affect what material is included or excluded to fit within time parameters (Cotton and Coleman 2008). In-service training in Canada appears to be similarly fragmented. Some services provide an hour of training, up to 40 hours, with the format of training delivery also varying (Coleman and Cotton 2010a). Coleman and Cotton (2010a) found that rural services - such as remote detachments of the Royal Canadian Mounted Police (RCMP) - relied on online training; whereas urban services tended to have a combination of classroom instruction and online components.

Ultimately, Oliva, Morgan, and Compton (2010) argue that the overall goal of mental health training is to provide officers with the skills to successfully de-escalate a crisis situation without increasing the chance of police liability or injury. Within the last few decades, however, police services in Canada and elsewhere have begun implementing specialized responses to these calls, such as CITs and CRTs, in an attempt to improve interactions with this population and their respective outcomes (Butler 2014).

\section{Crisis Intervention Teams}

CITs - also known as the Memphis Model - are a frontline mental health response that was developed in the city of Memphis, Tennessee subsequent to a police-involved death of a PwPMI in 1987 (Steadman et al. 2000). This response type seeks to improve police training, improve the quality of life for PwPMI, and emphasizes the need for cooperative and collaborative partnerships between the police, the mental health system, and various community-based mental health programs and services (Dupont et al. 2007; Bonfine, Ritter, and Munetz 2014; Wells and Schafer 2006; Wood and Watson, 2017).

Evaluations conducted on CITs in the United States has displayed favourable results. For example, CIT officers have improved knowledge of mental illness (Compton et al. 2014a; Wells and Schafer, 2006; Ellis 2014), improved attitudes towards PwPMI 
(Compton et al. 2014a; Compton, Esterberg, McGee, Kotwicki, and Oliva 2006; Demir, Broussard, Goulding, and Compton 2009; Ellis 2014), a higher tendency to choose a referral to a community-based mental health service or transfer to a hospital over arrest (Compton, Bakeman, Broussard, Hankerson-Dyson, Husbands, Krishan, StewartHutto, D'Orio, Oliva, Thompson, and Watson 2014b; Steadman et al. 2000; Franz and Borum 2011), improved de-escalation skills (Compton et al. 2014b), improved comfort and confidence when interacting with PwPMI (Compton et al. 2014a; Wells and Schafer 2006), and lowered use of physical force (Compton, Demir Neubert, Broussard, McGriff, Morgan, and Oliva 2011; Morabito, Kerr, Watson, Draine, and Angell 2012; Morabito, Socia, Wilk, and Fisher 2017).

CIT, however, is found to be less common in other parts of the world. In Canada, for example, reports suggest that CITs - or some modified form of the Memphis Model have been implemented in Halifax, Nova Scotia; Hamilton, Ontario; the Lower Mainland in British Columbia; and select detachments of the Ontario Provincial Police (Coleman \& Cotton, 2010a; Durbin et al. 2010a; Iacobucci 2014; Wood, Swanson, Burris, and Gilbert 2011), but little is known empirically about these Canadian CITs. Coleman and Cotton (2010b) suggest that, in contrast to the United States, death of officers and/or PwPMI during interactions - especially those involving firearms - is a much rarer occurrence in Canada. Thus, Canadian police services have been more likely to include civilian personnel in crisis interventions and have tended to gravitate toward CRTs (Butler 2014; Coleman and Cotton 2010a; Durbin et al. 2010a; Iacobucci 2014; Wood et al. 2011).

\section{Co-Response Teams}

Unlike CITs, which are primarily a frontline response, CRTs are - though, depending on the jurisdiction - comprised of an officer and a mental health practitioner who corespond to crisis calls at the request of first-responding officers (Iacobucci 2014). Though CRTs have received far less empirical attention than CITs, the objectives of both responses are similar (e.g., de-escalation, reduce/prevent injuries, diversion to hospital/community-based services, etc.), and CRTs are more commonly employed in jurisdictions such as the United Kingdom (e.g., Jennings and Matheson-Monnet 2017; Dyer, Steer, and Biddle 2015) and Australia/New Zealand (e.g., Furness et al. 2016; Huppert and Griffiths 2015; Lee at al. 2015; Meehan et al. 2019). CRTs are also employed in the United States (e.g., Rosenbaum 2010; Helfgott et al. 2016; White and Weisburd 2017; Bailey et al. 2018; Morabito et al. 2018; Yang, Gill, Kanewske, and Thompson 2018), though to a lesser extend in comparison to CITs. 
In Canada, some variation of CRTs are implemented in several jurisdictions, such as Toronto, Ontario; Halifax, Nova Scotia; Hamilton, Ontario; Peel Region, Ontario; Halton Region, Ontario; and Vancouver, British Columbia (Butler 2014; Coleman and Cotton 2010a; Iacobucci, 2014; Wilson-Bates 2008; Wood et al. 2011). Findings on the Mobile Crisis Intervention Teams (MCIT) in Toronto suggest that they divert more PwPMI to hospital than non-MCIT officers (Lamanna et al. 2018), and that individuals who had contact with MCIT reported having positive encounters (Lamanna et al. 2018; Kirst et al. 2014), especially in instances where the mental health practitioner took the lead (Kirst et al. 2014).

In Halifax, Kisley et al. (2010) evaluated the Mental Health Mobile Crisis Team (MHMCT) of the Halifax Regional Police Service (HRPS) and found that although calls for the team increased significantly following implementation, the time spent at a crisis by the MHMCT was significantly lower than non-MHMCT officers. Additionally, PwPMI who had contact with the MHMCT reportedly showed greater engagement with outpatient services and other mental health services than PwPMI who encountered non-MHMCT officers (Kisley et al. 2010).

In Hamilton, the Hamilton Police Service (HPS) deploy what has been described as one of the most robust approaches to PwPMI calls in Canada (Ghebreslassie 2017): a CIT, a Crisis Outreach and Support Team (COAST), and the Mobile Crisis Rapid Response Team (MCRRT). COAST is comprised of psychiatric nurses, mental health practitioners, social workers, occupational therapists, and plain-clothed police officers who attends calls at the request of first responding officers; whereas the MCRRT is made up of an officer-mental health practitioner pair (Fahim, Semovski, and Younger 2016). Uniquely, however, the MCRRT is a primary, frontline response, which departs from the status quo of CRTs being a secondary response. Findings on the MCRRT suggest that it has been effective at diverting PwPMI to community-based services and reducing unnecessary transfers to hospital by 49\% (Fahim et al. 2016).

Ultimately, the type of response - or combination of responses - that police services deploy will depend on a variety of factors that may be unique to the jurisdiction of that service, such as demographics, urban or rural geographies, local programs and services, and the prevalence of PwPMI contacts, among other factors (Butler 2014; Reuland et al. 2009; Pelfrey and Young 2019). Thus, while these responses may be broadly defined as 'CIT' or 'CRT' across jurisdictions, their structure and composition may differ. 


\section{Challenges of $\mathrm{CITs}$ and CRTs}

While the literature on CITs/CRTs seems promising, there is also evidence documenting their challenges. For example, most literature on these responses stresses the need for a central and identifiable drop off location for PwPMI with a 'norefusal' policy and rapid streamlined intakes (Deane et al. 1999; Steadman et al. 2000; Dupont et al. 2007); however, this is not usually employed in practice. For example, in Toronto, MCIT officers reportedly wait an average of two hours before custody is transferred (Iacobucci 2014). Though more recent research suggests that this average is now closer to 60 minutes (Lamanna et al. 2018). Relatedly, officers may wait long hours to only find that the individual will not be admitted or may be admitted and discharged only a few hours later (Canada et al. 2010).

As a consequence of long wait times, CITs/CRTs may not be able to respond to other individuals who may be in crisis (Iacobucci 2014). While the link between wait times and hampered CIT/CRT response rates has yet to be empirically explored, drastically low response rates in various Canadian and American jurisdictions (e.g., Durbin et al. 2010b; Iacobucci 2014; Steadman et al. 2000) suggest that this may be a contributing factor alongside other limitations, such as low CIT/CRT staffing (Steadman et al. 2000).

A further challenge, particularly with respect to CRTs, is that they are disproportionately a secondary response (Ghebreslassie 2017). In the context of the TPS MCIT, Iacobucci (2014:225) argues that, “... it is unfortunate that police officers without specialized training in mental health crises are required to make a crisis situation safe before the professionals most capable of managing and de-escalating that crisis - the MCIT - are allowed to intervene." Additionally, CRTs usually do not operate $24 / 7$, thus relying on a traditional frontline response when they are off-duty (Iacobucci 2014).

Moreover, the implementation of a CIT/CRT may also be improbable for some jurisdictions, especially rural locales who already struggle to address PwPMI calls with their existing resources (Yang et al. 2018). Interviews with American CIT stakeholders in rural communities found that sending an officer for week-long training may be difficult - especially as there may only be a few officers who work full-time - and that the cost to have an officer CIT trained may be far beyond the available budget (Skubby et al. 2013). 


\section{The Current Study}

While the aforementioned challenges of CITs and CRTs are not exhaustive, they do suggest potential areas of concern that may diminish the potential effectiveness of either of these responses. With CFS increasingly containing components of perceived mental health, and police services presumably shifting resources to establish CITs and/or CRTs for said calls, it is important to understand the challenges that these responses may endure. With little research to-date on these challenges, particularly within the Canadian context, the primary objective of this study is to document the perceived challenges faced by CITs/CRTs from a Canadian perspective. Additionally, as the extant empirical literature on CITs and CRTs in Canada is virtually non-existent, the secondary objectives of the current study are to determine which Canadian police services employ a CIT and/or CRT, as well as to determine the composition of said responses.

\section{Methodology}

In light of our objectives, we elected to approach the present study through a mixed methodology. To that end, we first invited one police officer from most Canadian police services to take part in an online survey comprised of open and closed-ended questions that was principally used to gather data with respect to which Canadian police services employed a CIT/CRT, as well as their respective compositions.

Greenland and Alma (2016) show that as of 2016, there were 184 police services in Canada: 144 municipal, three provincial, one federal, and 36 First Nations. For participant recruitment, we compiled a list of all Canadian police services at all levels. Then, through search engine queries, we sought to determine whether each service had an officer who was in a mental health-related position. If the service had such officers, and their contact information was available online, then the survey invitation was emailed to them directly. Otherwise, survey invitations were emailed to the police service's general inbox with a request that the invitation be forwarded to the single most appropriate individual working at their organization. Police services, however, were excluded from participating if: (1) they did not have a website; (2) there was no email address on their website; and/or (3) the service was predominantly Frenchspeaking and had no English version of their website. In total, the survey invitation was sent to 102 Canadian police services in October 2017, with follow-up reminder emails sent in December 2017 and January 2018. 
Upon completion of the survey, participants were invited to take part in a confidential, semi-structured telephone interview. Those who indicated their interest were contacted via email to supply a letter of consent, and to set up a date and time for the interview. The purpose of the interviews was to gather data with respect to the perceived challenges of CITs/CRTs in the Canadian context. All interviews were conducted between December 2017 and February 2018, and lasted 30-to-75 minutes in length. As an incentive for participation, five dollars was donated to the Canadian Police Association Robert Warner Memorial Fund for each survey completed, and ten dollars for every interview completed.

In terms of data analysis, most survey data was exported and converted into descriptive tables; whereas interview transcripts underwent a coding process. As there is little research on challenges endured by CITs/CRTs in Canada, we undertook an exploratory, inductive coding approach. More specifically, we employed Braun and Clarkes (2006) thematic analysis method in which themes were derived from the data, as opposed to an a priori selected theory or coding framework. Coding was the sole responsibility of the first-author who open-coded the interview transcripts, subsequently organizing them into themes. The coding process was repeated a second time to assess for the reliability of the identified themes. There was a high level of agreement between the two coding sessions (Landis and Koch 1977:165; $K=0.87$ ).

\section{Results}

Twenty-three Canadian police services completed the survey for a response rate of $22.5 \%$. Many provinces had at least one service participate, the most being located in Ontario ( $\mathrm{n}=10 ; 43.5 \%)$. The remaining responding services were located in $\mathrm{BC}(\mathrm{n}=6$; $26.1 \%)$, Saskatchewan ( $\mathrm{n}=3 ; 13 \%)$, Manitoba $(\mathrm{n}=1 ; 4.3 \%)$, Quebec $(\mathrm{n}=1 ; 4.3 \%)$, Prince Edward Island ( $\mathrm{n}=1 ; 4.3 \%)$, and Nova Scotia $(\mathrm{n}=1 ; 4.3 \%)$ (Table 1$)$.

\section{[TABLE 1 ABOUT HERE]}

Most services described PwPMI interactions as very common ( $\mathrm{n}=18,78 \%)$; whereas the remaining indicated these interactions were somewhat common $(\mathrm{n}=4 ; 17 \%)$ or rare $(\mathrm{n}=1 ; 4 \%)$ (Table 1$)$.

\section{Deployment and Composition of CITs/CRTs in Canada}

Of the 23 Canadian police services that participated in the current study, 17 (76\%) indicated that they have a CIT or CRT implemented within their organization in one of five ways: nine (53\%) deploy their CRT as an officer-mental health practitioner pair, 
two (12\%; Nelson, London) deploy their CRT as an on-call crisis team, two (12\%; Brantford, York Region) deploy both the pair and the crisis team, one (6\%; ChathamKent) deploys a combination of a CRT and CIT, and 3 (17\%) deploy officers who work in a hybrid CRT/liaison role (New Westminster, Port Moody) or only respond to existing clients (Windsor). Among the 20 unique responses deployed by the 17 services, most ( $\mathrm{n}$ $=16 ; 80 \%)$ are requested by the frontline. Of the four first-responses, one $(5 \%$; Chatham-Kent) is a CIT and the remaining $(\mathrm{n}=3 ; 15 \%)$ are CRTs (Brantford, York Region, Saskatoon) (Table 2).

\section{[TABLE 2 ABOUT HERE]}

As indicated in Table 2, the composition of these responses further vary in other areas as well. For example, variations can be found in whether officers are assigned to, or volunteer for, CIT/CRT positions. More specifically, among the 17 services with a CIT/CRT, two (12\%) services indicated that officers volunteer, six (35\%) services indicated that officers are assigned, and another six (35\%) indicated that officers can either volunteer or be assigned to CIT/CRT positions. Further, after being in these positions, eight (47\%) services indicated that officers are rotated out into a new position within the organization, whereas five (29\%) services indicated that officers remain on their CIT or CRT indefinitely. Variations are also evident with respect to hours of operation and hospital wait times; however, these areas were also discussed by our interview participants, thus we elaborate on them below.

\section{Perceived Challenges of Canadian CRTs}

Ten officers from ten of the survey-participating services (43.5\%) elected to participate in a follow-up telephone interview. All interview participants were from CRT-deploying services, and as such, the subsequent section focuses on the perceived challenges of CRTs. In order to maintain confidentiality, participants are referred to by a participant number.

Chronic and High Calls for Service. One of the first challenges identified by six participants was that PwPMI generate a high number of CFS, which, as explained by this officer, can take a significant amount of time:

I think the challenges are that these calls for service are going up. I know they always say, 'crime is going down', 'your file count is going down', and 'crimes, etc.' but it seems as though the mental health component is going up. And the reality is, these calls do take some time, so it could be, from start to end, four hours... (Participant 2) 
Another officer echoed the same issue by indicating that PwPMI can potentially account for a large portion of calls:

... we are dealing with an increasing number of disturbance calls involving mental health crisis, suicidal persons, [which] are certainly trending up. If you look across Canada, I've heard reports that police are dealing with someone in a mental health crisis - or where mental health is at least a factor - in as low as $5 \%$ and as high as $20 \%$ of calls (Participant 7 )

In addition to high CFS, three participants raised the issue of chronic calls for the same person(s). This officer, for example, describes a chronic case at their service, leading to frustration for officers:

... you're dealing with the same person - or people - over a period of time. I'll give you an example. There's one particular person here that we've dealt with 23 times this past year [...] It was the frustration of having to detain them under the Involuntary Psychiatric Treatment Act, [and] taking them to the hospital only for them to be released... (Participant 1)

Furthermore, high and chronic CFS can be further exacerbated within jurisdictions which have a high transient population, as identified by four participants. As this population is not within the same jurisdiction at all times, officers indicated that it was difficult to provide care to individuals who may be in the jurisdiction of one health authority and police service one day, and in the jurisdiction of another the next day: “... the integration and collaboration among, you know, people that move from one area to another area, or they're back and forth, they live in a couple different places, and how to share care for those individuals. That's challenging" (Participant 8).

Lack of Social Supports and Resources. The high and chronic CFS may be even further exacerbated when social supports and resources for mental illness may be lacking, as identified by five participants. For example, one officer discussed the limited room available at the local hospital, which can become an issue following an apprehension: "There's only one room at the hospital, and it's not uncommon for us to pick up one and be dealing with him at the hospital and go out and grab another one and come up to the hospital and they don't have space" (Participant 3). Another officer identified that they at times have to drive to another city because the local hospital may be unequipped to handle certain individuals: 
We do have a hospital locally here...however, they are a smaller community-based hospital. They would probably be fine with the 'no flight risk' cooperative suicidal individual, but someone in a drug-induced psychosis, etc., etc., they don't have a lot of facilities, and simply don't have the staff to work around that... so we drive to a different city, to a larger hospital facility [where] they are equipped for it (Participant 5)

Furthermore, a lack of resources or community-based mental health services can also leave individuals, particularly those who do not meet the criteria for an apprehension, stuck with nowhere to go:

Resourcing can be really tough to assist folks, especially if they're not meeting that criteria for an apprehension under the Mental Health Act... Sometimes there is very little that can be done for folks... Sometimes if there is no place like shelters, or friends, or anything that people are able to transport to... it's transporting them just to a Tim Hortons [coffee shop] and literally buying them a coffee out of our own pockets just so they can stay warm for the night. (Participant 5)

This officer further added that without basic pillars, and resources which can help provide those pillars, it is very difficult to help stabilize individuals in the community:

... if I think of my sickest folks, and people who have done well, and those still struggling to do well - the ones that aren't doing well are the ones that are chronically homeless or constantly evicted from their place of residence. When you don't have that simple stability, or your basic pillars, right? Your nutritional needs, your housing needs, all those things. How do we expect someone to comply with mental health treatment? (Participant 5)

Moreover, availability of those from the mental health system can be a challenge as well. This challenge can be faced by police services where mental health practitioners do not have the flexibility to attend a call if needed:

Often the mental health clinicians don't have work issued cellphones, so they're desk line only, and they're often tied up in appointments. They're often on a prescheduled full day of cases so they don't have flexibility to just leave the office and go do a crisis response or outreach response (Participant 4)

Similarly, availability can be a challenge faced by individuals who require psychiatric help. As this officer points out, wait times can be very long, and at times, can result in 
chronic calls for service:

... they base it, I guess, to a certain extent on the severity of the situations that people are dealing with, but sometimes people are waiting for six, eight months, or a year to see a psychiatrist. And that's, for the most part, I would say unacceptable because we see them maybe 20 , or 30 , or 100 times before they even get to the psychiatrist (Participant 10)

Another officer stated that their CRT does have access to a psychiatrist through the local health authority, but are not available when needed.

Hours of Operation. The survey results suggest that of the 17 services with a CIT/CRT, only one (London; 6\%) is available 24 hours a day. The remaining services $(\mathrm{n}=16 ; 94 \%)$ have various scheduled hours and days of operation for their respective responses (Table 2). Three officers indicated that the hours of operation for their CRT results in no coverage at certain times, leaving the frontline responsible for the call: "... if we have a call at [time], there's no mental health team available. It would be nice to have 24-hour availability - more teams available" (Participant 10). Another officer adds that CRT hours of operation are based around when they are most needed, and that there are contractual considerations in terms of equal work hours for CRT officers:

... we only have coverage $40 \%$ of the time... They work a day and a night with each one, so they're not always available 24/7. We've constructed their hours so that, when we did an analysis of the calls, their night shifts are [time] to [time], and their day shifts are [time] to [time]. And we kind of did that with the sense of, 'when are they needed?' But then there's also some contractual considerations that we have to do in terms of an equal amount of nights and days... (Participant 7)

Large Jurisdiction. Another challenge indicated by two officers was the size of their jurisdiction. For instance, one officer believed that their service's investment into their CRT was not as good as they expected due to the size of their jurisdiction:

I think the jurisdiction is too big. I don't think we're getting a level of service from the crisis response team that we need. I think the service needs to be expanded, and so we're currently in partnership with the health authority here looking at how we might be able to expand that service (Participant 9)

Staffing and Funding. Another challenge identified by two participants was CRT staffing and funding. One officer stated that their response cannot get to certain people “... because we just don't have the manpower” (Participant 6). This can be 
further exacerbated, as explained by one participant, by CRT officers being on leave, leading the response to be under-staffed. Moreover, another participant indicated that management realizes that they could expand their CRT, but do not have the resources to do so:

I think management really recognizes that we could expand... but resourcing wise, we just don't have the budget - or anything - to support that at that time. I think there's recognition we could be having a couple more people up here, but within the same sense we're limited within what we get funded for... (Participant 5)

Hospital Wait Times. The length of wait times before custody of an individual is transferred to the hospital was also identified as a challenge by five participants. One participant said that, “... if we do apprehend somebody and take someone to hospital, our average wait time is about two-and-a-half hours and it can be much longer... Four to six hours." Survey results suggest that of the 17 services with a CIT/CRT, 11 (65\%) had a wait time of 2-3 hours. Four services (24\%) had a wait time of $0-1$ hours, with the remaining two services (12\%) reporting a wait time of 4-5 hours (Table 2).

CRT Evidence. Evidence of CRT effectiveness was a challenge that was identified by three participants. For example, before establishing their CRT, one officer attempted to look for any available data from other jurisdictions, but was unable to find much:

... we looked at any available data that we could get in the policing world, and quite frankly, police services aren't very good at sharing their data or some of their programs, at least not in a peer-reviewed sense. And we don't publish them typically, so it's tough to dive down and get reports and data because they're not readily available. So, long story short is, we did our own pilot. It was a very successful pilot (Participant 7)

The same officer continues by saying that more research can illustrate that CRTs are an evidence-based response, and thus can receive more funding: "I think that's why the more research and the more we can illustrate that co-response is an evidencebased response, the more likely police agencies are able to get funding" (Participant 7). On a similar note, another officer intuitively believes that CRTs are working, but research partnerships with academia are needed to confirm it:

Intuitively we know these teams are working, but until police can also determine better ways to gather the statistics, the data, the only way we're going to be able to do it is by partnering with academia... so that we can make sure that what 
we're doing actually is working, and identify areas where we can improve (Participant 9)

\section{Discussion}

The purpose of this study was two-fold. Our principal objective was to document the perceived challenges of CITs/CRTs in the Canadian context, with a secondary objective of gathering additional information about the composition of these responses within Canada. To our knowledge, this is the first Canadian study to do so on a national scale. We find that, of the 23 police services that participated in the present study, most had some form of CIT or CRT established within their organization, the most common of which was the latter - aligning with Coleman and Cotton (2010b) who suggest that CRTs are more common in Canada.

Further, although the most common deployment structure among the sample is an officer-mental health practitioner pair - which are also deployed within Canadian jurisdictions that did not take part in the present study (Iacobucci 2014; Fahim et al. 2016; Kisley et al. 2010) - there were variations in how these responses were composed. For example, variations were evident with respect to hours of operation and whether CRT positions were filled on a volunteer basis, both of which may have implications on police-PwPMI contacts. More specifically, the lack of a 24-hour deployment model - also identified as a challenge by interview participants - results in the frontline being sent to calls that otherwise would have been addressed by a CRT. While Canadian officers do receive training on mental health (Cotton and Coleman 2008; Coleman and Cotton 2010a), the literature suggests that CRT contacts with PwPMI not only result in more positive interactions, but also better outcomes in contrast to frontline interactions (Lamanna et al. 2018; Kirst et al. 2014). Relatedly, CIT-specific research on officer assignment to these positions suggests that officers who volunteer are associated with better outcomes in terms of attitudes, skill, and behaviours (Compton et al. 2017). This, however, has yet to be tested within a CRT context. Finally, most responses in the sample were characterized as a secondaryresponse. This, too, has implications as those most capable are not the first on the scene (Iacobucci 2014). However, three CRTs in the sample, as well as responses elsewhere (e.g., Hamilton; Fahim et al. 2016), have deployed their CRT as a first response, thus presumably enabling greater PwPMI engagement.

Moreover, as identified by interview participants, these responses - and CRTs more specifically in the context of this study - are perceived to endure many challenges. High and chronic CFS, lack of social supports and resources, hours of operation, 
staffing and funding, and hospital wait times, among others, are challenges which have been previously documented in individual jurisdictions across Canada and elsewhere, both in CRT and frontline-only contexts (Vaughan and Andresen 2018; Iacobucci 2014; Canada et al. 2010; Steadman et al. 2000; Cotton 2004; Cotton and Coleman 2010; Forchuck et al. 2010). Though some of the identified challenges may be outside of the scope of policing (e.g., lack of social supports), they may ultimately lead to CRTs being unable to adequately assist PwPMI, link them to community-based services, or even attend CFS. To address some of these challenges, and to improve police-PwPMI interactions in the light of police-involved deaths, recommendations have emphasized that there be greater deployment of CRTs at police organizations, 24/7 availability, implementing CITs in conjunction with CRTs, and further training (e.g., Iacobucci 2014).

While such recommendations seem logical, the current funding context of Canadian policing makes following through on such recommendations infeasible. Though crime has steadily decreased in Canada in the last 20 years (Allen 2018), police expenditures have nearly doubled within the same timeframe (Conor 2018) thus causing concern about the overall economics of policing (Griffiths 2014; Huey and Ricciardelli 2016; Kiedrowski, Petrunik, Macdonald, and Melchers 2013). And as identified by some interview participants, there is little room within these budgets to allow for CRT expansion.

However, as suggested by one of the participants, a plausible solution to this issue may be further research. More specifically, the development of a more robust evidence base for CRTs may assist police services in securing or redirecting the necessary funding for CRT implementation and/or expansion. As it currently stands, the literature has a disproportionate focus on American CITs; whereas reviews of peer-reviewed literature have suggested that while the evidence on CITs/CRTs is promising, more evidence is needed (Bird and Shemilt 2019; Shapiro et al. 2015; Taheri 2016; Watson, Compton, and Draine 2017; Dewa et al. 2018; Puntis et al. 2018). In the Canadian context more specifically, peer reviewed evidence on CRTs is only available from a small proportion of jurisdictions that employ them - Toronto (Lamanna et al. 2018), Hamilton (Fahim et al. 2016), and Halifax (Kisley et al. 2010) - ultimately resulting in a very limited and under-developed Canadian evidence base.

It is therefore clear that more research must be conducted on CRTs in the Canadian context, for three important reasons: First, there are significant gaps in the literature with respect to CRT implementation and effectiveness. Areas such as optimal response 
composition (e.g., hours of operation, first/second response, voluntary/assigned, etc.), training, objective attainment, interaction outcomes, cost-savings, and the consequences of endured challenges are all areas which would not only provide evidence with respect to effectiveness, but also efficiencies and solutions to challenges. Second, making evidence-based decisions on CRTs can remove these responses from any concerns surrounding the economics of policing (Griffiths 2014; Huey and Ricciardelli 2016; Kiedrowski et al. 2013). That is, if they are determined to be an evidence-based response, then there will presumably be less concern about portions of police budgets being spent on them. Finally, should the evidence point to CRTs being effective, and even cost-cutting (e.g., reduced CFS, reduced chronic interactions, etc.), then there may be a potential for even more funds to be available for CRTs that would then enable further expansion, thus possibly mitigating some of the identified challenges.

\section{Limitations}

As with all empirical work, this study is not without limitations. First, while our intention was to include all Canadian police services, the nature of our sampling procedure unfortunately led to an exclusion of several services that did not meet certain criteria. This, in turn, limited our ability to reach certain rural and Frenchspeaking services that may have had different compositions and perceived challenges than what has been presented herein. Second, the RCMP did not participate in the present study, nor did any provincial police services, both levels of which account for a significant proportion of policing in Canada, geographically. Third, the standardized nature of the survey may have prevented participants from elaborating on various unforeseen aspects of their CIT/CRT. Finally, while not irregular from other policing research (Coleman and Cotton 2010a; Huey et al. 2017; Nix et al. 2019), the present study experienced a low survey response rate, which consequently impacted our ability to develop a more robust understanding of CIT and CRT composition in the Canadian context, as well as to recruit interview participants. While we acknowledge that the size of our survey and interview samples are a weakness of this study given our overall sampling frame, there remains a significant lack of research on these responses within the Canadian context, particularly with respect to their endured challenges. As such, the results presented herein should be treated as exploratory from which future research may use as a point of initiation. 


\section{Conclusion}

To-date, there has been a dearth of research, particularly within the Canadian context, that has examined the use of CITs and CRTs. Thus, through a mixed methodological approach, the present study sought to address a portion of this knowledge gap around the composition of CITs and CRTs in the Canadian context, as well as any perceived challenges. The findings suggest that although a large proportion of the sample employ a CIT and/or CRT in practice, their respective compositions may differ widely by jurisdiction. Further, specifically with respect to CRTs, interview participants identified numerous perceived challenges that are endured by this response-type, such as high and chronic CFS, lack of social supports and resources, hours of operation, staffing and funding, and hospital wait times, among others. Ultimately, both the compositional structure of these responses and any endured challenges can have significant implications for their successful deployment within the Canadian context. Future research is undoubtedly needed on many areas relating to CITs and CRTs, especially as it relates to optimal and effective composition, as well as understanding the consequences of endured challenges and how challenges can be effectively addressed.

\section{References}

Adams, Kenneth. 2004. What we know about police use of force. In Contemporary Policing: Controversies, Challenges, and Solutions. Quint C. Thurman and Jihong Zhao. Los Angeles: Roxbury.

Allen, Mary. 2018. Police-reported crime statistics in Canada, 2017. Juristat. Statistics Canada Catalogue no. 85-002-X.

Bailey, Katie, Staci Rising Paquet, Bradley R. Ray, Eric Grommon, Evan M. Lowder, and Emily Sightes. 2018. Barriers and facilitators to implementing an urban co-responding police-mental health team. Health and Justice, 6(21).

Bird, Karen Schucan, and Ian Shemilt. 2019. The crime, mental health, and economic impacts of prearrest diversion of people with mental health problems: A systematic review. Criminal Behaviour and Mental Health: 1-15.

Bohrman, Casey, Amy Blank Wilson, Amy Watson, and Jeff Draine. 2018. How police officers assess for mental illness. Victims \& Offenders, 13(8): 1077-1092. 
Bonfine, Natalie, Christian Ritter, and Mark R. Munetz. 2014. Police officer perceptions of the impact of Crisis Intervention Team (CIT) programs. International Journal of Law and Psychiatry, 37(4): 341-350.

Boyce, Jillian, Cristine Rotenberg, and Maisie Karam. 2015. Mental Health and Contact with Police in Canada, 2012. Juristat. Statistics Canada Catalogue no. 85-002-X.

Brink, Johann, James Livingston, Sarah Desmarais, Erin Michalak, Simon VerdunJones, Victoria Maxwell, Rick Parent, and Camia Weaver. 2011. A Study of how people with mental illness perceive and interact with the police. Mental Health Commission of Canada, Calgary.

Braun, Virginia and Victoria Clarke. 2006. Using thematic analysis in psychology. Qualitative Research in Psychology, 3(2): 77-101.

Butler, Amanda. 2014. Mental Illness and the Criminal Justice System: A Review of Global Perspectives and Promising Practices. University of British Columbia: International Centre for Criminal Law Reform and Criminal Justice Policy.

Canada, Kelli E., Beth Angell, and Amy C. Watson. 2010. Crisis Intervention Teams in Chicago: Successes on the ground. Journal of Police Crisis Negotiations, 10(1-2): 86100 .

Charette, Yanick, Anne G. Crocker, and Isabelle Billette. 2011. The judicious judicial dispositions juggle: Characteristics of police interventions involving people with a mental illness. The Canadian Journal of Psychiatry, 56(11): 677-685.

Coleman, Terry G. and Dorothy Cotton. 2010a. Police Interactions with Persons with a Mental Illness: Police Learning in the Environment of Contemporary Policing. Ottawa: Mental Health Commission of Canada.

Coleman, Terry G. and Dorothy H. Cotton. 2010b. Reducing risk and improving outcomes of police interactions with people with mental illness. Journal of Police Crisis Negotiations, 10(1-2): 39-57.

Compton, Michael T., Roger Bakeman, Beth Broussard, Dana Hankerson-Dyson, Letheshia Husbands, Shaily Krishan, Tarianna Stewart-Hutto, Barbara M. D’Orio, Janet R. Oliva, Nancy J. Thompson, and Amy C. Watson. 2014a. The police-based Crisis Intervention Team (CIT) model: I. Effects on officers' knowledge, attitudes, and skills. Psychiatric Services, 65(4): 517-522. 
Compton, Michael T., Roger Bakeman, Beth Broussard, Dana Hankerson-Dyson, Letheshia Husbands, Shaily Krishan, Tarianna Stewart-Hutto, Barbara M. D'Orio, Janet R. Oliva, Nancy J. Thompson, and Amy C. Watson. 2014b. The police-based Crisis Intervention Team (CIT) model: II. Effects on level of force and resolution, referral, and arrest. Psychiatric Services, 65(4): 523-529.

Compton, Michael T., Berivan N. Demir Neubert, Beth Broussard, Joanne A. McGriff, Rhiannon Morgan, and Janet R. Oliva. 2011. Use of force preferences and perceived effectiveness of actions among Crisis Intervention Team (CIT) police officers and nonCIT Officers in an escalating psychiatric crisis involving a subject with schizophrenia. Schizophrenia Bulletin, 37(4): 737-745.

Compton, Michael T., Michelle L. Esterberg, Robin McGee, Raymond J. Kotwicki, and Janet R. Oliva. 2006. Crisis Intervention Team training: Changes in knowledge, attitudes, and stigma related to schizophrenia. Psychiatric Services, 57(8): 1999-1202. Compton, Michael T., Roger Bakeman, Beth Broussard, Barbara D'Orio, and Amy C. Watson. 2017. Police officers' volunteering for (rather than being assigned to) crisis intervention team (CIT) training: Evidence for a beneficial self-selection effect. Behavioral Sciences \& the Law, 35: 470-479.

Conor, Patricia. 2018. Police resources in Canada, 2017. Juristat. Statistics Canada Catalogue no. 85-002-X.

Cotton, Dorothy. 2004. The attitudes of Canadian police officers toward the mentally ill. International Journal of Law and Psychiatry, 27: 135-146.

Cotton, Dorothy and Terry Coleman. 2008. A Study of Police Academy Training and Education for New Police Officers Related to Working with People with Mental Illness. Mental Health Commission of Canada and the Canadian Association of Chiefs of Police, Ottawa.

Cotton, Dorothy and Terry G. Coleman. 2010. Canadian police agencies and their interactions with persons with a mental illness: A systems approach. Police Practice and Research, 11(4): 301-314.

Crocker, Anne G., Kathleen Hartford, and Lisa Heslop. 2009. Gender differences in police encounters among persons with and without serious mental illness. Psychiatric Service, 60(1): 86-93. 
Deane, Martha Williams, Henry J. Steadman, Randy Borum, Bonita M. Veysey, and Joseph P. Morrissey. 1999. Emerging partnerships between mental health and law enforcement. Psychiatric Services, 50(1): 99-101.

Demir, Berivan, Beth Broussard, Sandra M. Goulding, and Michael T. Compton. 2009. Beliefs about causes of schizophrenia among police officers before and after Crisis Intervention Team training. Community Mental Health Journal, 45(5): 385-392.

Desmarais, Sarah L., James Livingston, Caroline L. Greaves, Kiersten L. Johnson, Simon Verdun-Jones, Rick Parent, and Johann Brink. 2014. Police perceptions and contact among people with mental illness: Comparisons with a general population survey. Psychology, Public Policy, and Law, 20(4): 431-442.

Dewa, Carolyn S., Desmond Loong, Austin Truijillo, and Sarah Bonato. 2018. Evidence for the effectiveness of police-based pre-booking diversion programs in decriminalizing mental illness: A systematic review. PLoS ONE, 13(6).

Dyer, Wendy, Melanie Steer, and Paul Biddle. 2015. Mental health street triage. Policing, 9(4): 377-387.

Dube, Paul. 2016. A matter of live and death. Ombudsman of Ontario, Toronto.

Dupont, Randolph, Sam Cochran, and Sarah Pillsbury. 2007. Crisis Intervention core elements. The University of Memphis School of Urban Affairs and Public Policy, Department of Criminology and Criminal Justice. Memphis, TN: CIT Center.

Durbin, Janet, Elizabeth Lin, and Brian Rush. 2010b. A Study of Hospital Emergency Service Use, Crisis Service Delivery and Police Response After Mental Health Systems Enhancements. Toronto: Centre for Addiction and Mental Health.

Durbin, Janet, Elizabeth Lin, and Natalia Zaslavska. 2010a. Police-citizen encounters that involve mental health concerns: Results of an Ontario police services survey. Canadian Journal of Community Mental Health, 29(29): 53-71.

Ellis, Horace A. 2014. Effects of a Crisis Intervention Team (CIT) training program upon police officers before and after Crisis Intervention Team training. Archives of Psychiatric Nursing, 28: 10-16.

Engel, Robin Shepard and Eric Silver. 2001. Policing mentally disordered suspects: A re-examination of the criminalization hypothesis. Criminology, 39(2): 225-252. 
Fahim, Christine, Valbona Semovski, and Jodi Younger. 2016. The Hamilton Mobile Crisis Rapid Response Team: A first-responder mental health service. Psychiatric Services, 67(8): 929.

Forchuk, Cheryl, Elsabeth Jensen, Mary-Lou Martin, Risk Csiernik, and Heather Atyeo. 2010. Psychiatric crisis services in three communities. Canadian Journal of Community Mental Health, 29: 73-86.

Franz, Stephanie and Randy Borum. 2011. Crisis Intervention Teams may prevent arrests of people with mental illness. Police, Practice and Research, 12(3): 265-272.

Frederick, Tyler, Chris O'Connor, and Jacek Koziarski. 2018. Police interactions with people perceived to have a mental health problem: A critical review of frames, terminology, and definitions. Victims \& Offenders, 13(8): 1037-1054.

Furness, Trentham, Tessa Maguire, Steve Brown, and Brian McKenna. 2016. Perceptions of procedural justice and coercion during community-based mental health crisis: A comparison study among stand-alone police responses and co-responding police and mental health clinician response. Policing, 11(4): 400-409.

Ghebreslassie, Makda

2017 Andrew Loku inquest calls for 24-hour crisis intervention teams, but how do they work? CBC News: http://www.cbc.ca/news/canada/toronto/andrew-loku-inquest-callsfor-24-hour-crisis-intervention-teams-but-how-do-they-work-1.4187173.

Girard, Vincent, Jean Pierre Bonin, Aurelie Tinland, Cyril Farnarier, Jean Francois Pelletier, Miriam E. Delphin, Michael Rowe, and Marie Claud Simeoni. 2014. Mental health outreach and street policing in the downtown of a large French city. International Journal of Law and Psychiatry, 37(4): 376-382.

Greenland, Jacob and Sarah Alam. 2017. Police Resources in Canada, 2016. Juristat. Statistics Canada Catalogue no. 85-002-X.

Griffiths, Curt Taylor. 2014. Economics of policing: Baseline of policing research in Canada. Public Safety Canada, Ottawa.

Hall, Barbara. 2014. Report of the Ontario Human Rights Commission on police use of force and mental health. Ontario Human Rights Commission, Toronto. 
Helfgott, Jaqueline B., Matthew J. Hickman, and Andre P. Labossiere. 2016. A descriptive evaluation of the Seattle Police Department's crisis response team officer/mental health professional partnership pilot program. International Journal of Law and Psychiatry, 44: 109-122.

Huey, Laura and Rose Ricciardelli. 2016. From seeds to orchards: Using evidencebased policing to address Canada's policing research needs. Canadian Journal of Criminology and Criminal Justice, 58(1): 119-131.

Huey, Laura, Brittany Blaskovits, Craig Bennell, Hina Kalyal, and Thomas Walker. 2017. To what extend do Canadian police professionals believe that their agencies are 'Targeting, Testing, and Tracking' new policing strategies and programs? Police Practice and Research, 18(6): 544-555.

Huppert, David and Matthew Griffiths. 2015. Police mental health partnership project: Police ambulance crisis emergency response (PACER) model. Australasian Psychiatry, 23(5): 520-523.

Iacobucci, Frank. 2014. Police Encounters with People in Crisis. Toronto Police Service, Toronto, Ontario.

Jennings, Paul and Catherine B. Matheson-Monnet. 2017. Multi-agency mentoring pilot intervention for high intensity service users of emergency public services: The Isle of Wight integrated recovery programme. Journal of Criminological Research, Policy and Practice, 3(2): 105-118.

Kiedrowski, John, Michael Petrunik, Todd Macdonald, and Ron Melchers. 2013. Canadian police board views on the use of police performance metrics. Public Safety Canada, Ottawa.

Kirst, Maritt, Renira Narrandes, Kate Francombe Pridham, Janani Yogalingam, Flora Matheson, and Vicky Stergiopoulos. 2014. Toronto Mobile Crisis Intervention Team (MCIT) Program Implementation Evaluation Final Report. St. Michael's Hospital. Toronto: Centre for Research on Inner City Health.

Kisely, Stephen, Leslie Anne Campbell, Sarah Peddle, Susan Hare, Mary Pyche, Don Spicer, and Bill Moore. 2010. A controlled before-and-after evaluation of a mobile crisis partnership between mental health and police services in Nova Scotia. Canadian Journal of Psychiatry, 55(10): 662-668. 
Lamanna, Denise, Gilla K. Shapiro, Maritt Kirst, Flora I. Matheson, Arash Nakhost, and Vicky Stergiopoulos. 2018. Co-responding police-mental health programmes: Service user experiences and outcomes in a large urban centre. International Journal of Mental Health Nursing, 27: 891-900.

Lamb, Richard H. and Leona L. Bachrach. 2001. Some perspective on deinstitutionalization. Psychiatric Services, 52(8): 1039-1045.

Landis, J. Richard and Gary G. Koch. 1977. The measurement of observer agreement for categorical data. International Biometric Society, 33(1): 159-174.

Lee, Stuart J., Phillipa Thomas, Chantelle Doulis, Doug Bowles, Kathryn Henderson, Sandra Keppich-Arnold, Eva Perez, and Simon Stafrace. 2015. Outcomes achieved by and police and clinician perspectives on joint police officer and mental health clinician mobile response unit. International Journal of Mental Health Nursing, 24: 538-546.

Livingston, James, Sarah L. Desmarais, Simon Verdun-Jones, Richard Parent, Eric Michalak, and Johann Brink. 2014. Perceptions and experiences of people with mental illness regarding their interactions with police. International Journal of Law and Psychiatry, 37(4): 334-340.

McNeilly, Gerry. 2017. Police interactions with people in crisis and use of force. Office of the Independent Police Review Director, Toronto.

Meehan, Tom, Janet Brack, Yolanda Mansfield, and Terry Stedman. 2019. Do policemental health co-responder programmes reduce emergency department presentations or simply delay the inevitable? Australasian Psychiatry, 27(1): 18-20.

Menzies, Robert J. 1987. Psychiatrists in blue: Police apprehension of mental disorder and dangerousness. Criminology, 25(3): 429-454.

Morabito, Melissa S., Amy N. Kerr, Amy Watson, Jeffrey Draine, Victor Ottati, and Beth Angell. 2012. Crisis Intervention Teams and people with mental illness: Exploring the factors that influence the use of force. Crime \& Delinquency, 58(1): 57-77.

Morabito, Melissa S., Kelly Socia, Amanda Wik, and William H. Fisher. 2017. The nature and extent of police use of force in encounters with people with behavioral health disorders. International Journal of Law and Psychiatry, 50: 31-37.

Morabito, Melissa S., Jenna Savage, Lauren Sneider, and Kellie Wallace. 2018. Police response to police with mental illnesses in a major U.S. city: The Boston experience 
with the co-responder model. Victims \& Offenders, 13(8): 1093-1105.

Nix, Justin, Justin T. Pickett, Hyunin Baek, and Geoffrey P. Alpert. 2019. Police research, officer surveys, and response rates. Policing and Society, 29(5): 530-550.

Oliva, Janet R., Rhiannon Morgan, and Michael T. Compton. 2010. A practical overview of de-escalation skills in law enforcement: Helping individuals in crisis while reducing police liability and injury. Journal of Police Crisis Negotiations, 10(1-2): 15-29.

Pelfrey, William V., Ania Young. 2019. Police crisis intervention teams: Understanding implementation variations and officer-level impacts. Journal of Police and Criminal Psychology.

Puntis, Stephen, Devon Perfect, Abirami Kirubarajan, Sorcha Bolton, Fay Davies, Aimee Hayes, Eli Harriess, and Andrew Molodynski. 2018. A systematic review of coresponder models of police mental health 'street' triage. BMC Psychiatry, 18.

Reuland, Melissa, Matthew Schwarzfeld, and Laura Draper. 2009. Law Enforcement Responses to People with Mental Illness: A Guide to Research-Informed Policy and Practice. New York: Council of State Governments Justice Centre.

Rosenbaum, Nils. 2010. Street-level psychiatry: A psychiatrist's role with the Albuquerque Police Department's Crisis Outreach and Support Team. Journal of Police Crisis Negotiations, 10: 175-181.

Schulenberg, Jennifer L. 2016. Police decision-making in the gray zone: The dynamics of police-citizen ecounters with mentally ill persons. Criminal Justice and Behaviour, 43(4): 459-482.

Shapiro, Gilla K., Andree Cusi, Maritt J. Kirst, Patricia O’Campo, Arash Nakhost, and Vicky Stergiopoulos. 2015. Co-responding police-mental health programs: A review. Administration and Policy in Mental Health, 42(5): 606-620.

Shore, Krystle and Jennifer A. A. Lavoie. 2018. Exploring mental health-related calls for police service: A Canadian study of police officers as 'frontline mental health workers'. Policing, 13(2): 157-171.

Skubby, David, Natalie Bonfine, Meghan Novisky, Mark R. Muntez, and Christian Ritter. 2013. Crisis intervention team (CIT) programs in rural communities: A focus group study. Community Mental Health Journal, 49(6): 756-764. 
Smetanin, Paul, Carla Briante, David Stiff, Sheeba Ahmad, and Minhal Kahn. 2011. The Life and Economic Impact of Major Mental Illnesses in Canada: 2011 to 2041. Toronto: RiskAnalytica, on behalf of the Mental Health Commission of Canada.

Steadman, Henry J., Martha Williams Deane, Randy Borum, and Joseph P. Morrissey. 2000. Comparing outcomes of major models of police responses to mental health emergencies. Psychiatric Services, 51(5): 645-649.

Taheri, Sema A. 2016. Do crisis intervention teams reduce arrests and improve officer safety? A systematic review and meta-analysis. Criminal Justice Policy Review, 27(1): 76-96.

Vaughan, Adam D. and Martin A. Andresen. 2018. The cost of mental health-related calls of police service: Evidence from British Columbia. In Evidence-Based Policing: An Introduction. Renee Mitchell and Laura Huey. Bristol: Policy Press.

Watson, Amy C., Patrick W. Corrigan, and Victor Ottati. 2004. Police officers' attitudes toward and decisions about persons with mental illness. Psychiatric Services, 55(1): 4953.

Watson, Amy C., Michael T. Compton, and Jeffrey N. Draine. 2017. The crisis intervention team (CIT) mode: An evidence-based policing practice? Behavioral Sciences \& the Law, 35: 431-441.

Wells, William and Joseph A. Schafer. 2006. Officer perceptions of police responses to persons with a mental illness. Policing: An International Journal of Police Strategies \& Management, 29(4): 578-601.

White, Clair and David Weisburd. 2017. A co-responder model for policing mental health problems at crime hot spots: Findings from a pilot project. Policing, 12(2): 194209.

Wilson-Bates, Fiona. 2008. Lost in Translation: How a Lack of Capacity in the Mental Health System in Failing Vancouver's Mentally Ill and Draining Police Resources. Vancouver, BC.

Wood, Jennifer D. and Amy C. Watson. 2017. Improving police interventions during mental health-related encounters: Past, present and future. Policing and Society, 27(3): 289-299. 
Wood, Jennifer, Jeffrey Swanson, Scott Burris, and Allison Gilbert. 2011. Police Intervention with Persons Affected by Mental Illness: A Critical Review of Global Thinking and Practice. New Brunswick, New Jersey: Centre for Behavioral Health Services \& Criminal Justice Research.

Yang, Sue-Ming, Charlotte Gill, L. Caitlin Kanewske, and Paige S. Thompson. 2018. Exploring police response to mental health calls in a non-urban area: A case study of Roanoke County, Virginia. Victims \& Offenders, 13(8): 1132-1152.

\section{Tables}

Table 1. Participating Police Services

\begin{tabular}{|c|c|c|c|}
\hline Police Service & Urban / Rural & \# of Officers & PiC Interactions \\
\hline \multicolumn{4}{|l|}{ British Columbia } \\
\hline Central Saanich & Rural & $0-100$ & Somewhat common \\
\hline Nelson & Urban & $0-100$ & Very common \\
\hline New Westminster & Urban & $101-200$ & Very common \\
\hline Port Moody & Urban & $0-100$ & Very common \\
\hline Vancouver & Urban & $>500$ & Very common \\
\hline Victoria & Urban & $201-300$ & Very common \\
\hline \multicolumn{4}{|l|}{ Manitoba } \\
\hline Winnipeg & Urban & $>500$ & Somewhat common \\
\hline \multicolumn{4}{|l|}{ Nova Scotia } \\
\hline Annapolis Royal & Urban & $0-100$ & Rare \\
\hline \multicolumn{4}{|l|}{ Ontario } \\
\hline Brantford & Urban & $101-200$ & Very common \\
\hline Brockville & Urban & $0-100$ & Very common \\
\hline
\end{tabular}




\begin{tabular}{|c|c|c|c|}
\hline Chatham-Kent & Both & $101-200$ & Very common \\
\hline Durham Region & Urban & $>500$ & Very common \\
\hline LaSalle & Both & $0-100$ & Somewhat common \\
\hline London & Urban & $>500$ & Very common \\
\hline Peel Region & Urban & $>500$ & Very common \\
\hline St. Thomas & Urban & $0-100$ & Very common \\
\hline Windsor & Both & $401-500$ & Very common \\
\hline York Region & Both & $>500$ & Very common \\
\hline \multicolumn{4}{|c|}{ Prince Edward Island } \\
\hline Charlottetown & Urban & $0-100$ & Very common \\
\hline \multicolumn{4}{|l|}{ Quebec } \\
\hline Mont-Tremblant & Both & $0-100$ & Somewhat common \\
\hline \multicolumn{4}{|l|}{ Saskatchewan } \\
\hline Regina & Urban & $401-500$ & Very common \\
\hline Saskatoon & Urban & $401-500$ & Very common \\
\hline Weyburn & Urban & $0-100$ & Very common \\
\hline
\end{tabular}

Table 2. Composition of CITs and CRTs

Police Service

British Columbia
Composition of Response 


\begin{tabular}{|c|c|}
\hline Central Saanich & $\begin{array}{l}\text { The Greater Victoria Region has a variety of } \\
\text { integrated units comprised of officers from this } \\
\text { region. The Integrated Mobile Crisis Response } \\
\text { Team (IMCRT) is comprised of nurses, } \\
\text { counsellors, child and youth mental health } \\
\text { clinicians, and two police officers - one from } \\
\text { Saanich and the other from Victoria. Officers } \\
\text { from Oak Bay and Central Saanich occasionally } \\
\text { fill in. } \\
\text { Hours of Operation: } 1200-2400,7 \text { days/week } \\
\text { Assign/Volunteer: Either | Rotation: } 3 \text { years } \\
\text { Response: Requested by frontline | Hospital } \\
\text { Wait Time: } 2-3 \text { hrs }\end{array}$ \\
\hline Nelson & $\begin{array}{l}\text { Work informally with a mental health team from } \\
\text { the health authority who can co-respond if } \\
\text { available. } \\
\text { Hours of Operation: } 0800-1600 \text {, Monday- } \\
\text { Friday } \\
\text { Assigned/Volunteer: - Rotation: - } \\
\text { Response: Requested by frontline | Hospital } \\
\text { Wait Time: } 0-1 \text { hrs }\end{array}$ \\
\hline
\end{tabular}




\begin{tabular}{|c|c|}
\hline New Westminster & $\begin{array}{l}\text { Two mental health-specific officers who work in } \\
\text { conjunction with those from the mental health } \\
\text { system. The two positions are a hybrid liaison/co- } \\
\text { responder position, but are not a dedicated co- } \\
\text { response (i.e., do not have a dedicated mental } \\
\text { health specialist partner). The positions also } \\
\text { provide support/consultation to the frontline, and } \\
\text { they co-respond on an 'as available/as } \\
\text { appropriate' basis with an available mental } \\
\text { health worker or the mental health worker of the } \\
\text { individual in crisis. } \\
\text { Hours of Operation: } 0700-1700, \text { Monday- } \\
\text { Friday } \\
\text { Assign/Volunteer: Volunteer | Rotation: } 5 \\
\text { years } \\
\text { Response: Requested by frontline | Hospital } \\
\text { Wait Time: } 2-3 \text { hrs }\end{array}$ \\
\hline Port Moody & $\begin{array}{l}\text { One mental health-specific officer who works on } \\
\text { a casual basis with mental health partners. } \\
\text { Provides support/consultation to the frontline } \\
\text { and liaises/co-responds with community mental } \\
\text { health teams as needed. } \\
\text { Hours of Operation: } 0700-1700 \text {, Tuesday- } \\
\text { Friday } \\
\text { Assigned/Volunteer: Assigned | Rotation: No } \\
\text { Response: Requested by frontline | Hospital } \\
\text { Wait Time: } 2-3 \text { hrs }\end{array}$ \\
\hline
\end{tabular}




\begin{tabular}{|c|c|}
\hline Vancouver & $\begin{array}{l}\text { Mental Health Unit - named 'Car } 87 \text { ' - is a co- } \\
\text { response with a nurse and an officer. There is a } \\
\text { morning and afternoon car (i.e., two teams/day). } \\
\text { Four officers are in this unit. Beyond the crisis } \\
\text { response, Vancouver also has five Assertive } \\
\text { Community Treatment Teams (ACT), with two } \\
\text { officers embedded within, that provide service } \\
\text { for clients who have been unsuccessful in } \\
\text { traditional care models. ACT can assist in finding } \\
\text { long-term care, housing, and more. Finally, an } \\
\text { Assertive Outreach Team (AOT) is made up of } \\
\text { four officers, nurses, and psychiatrists who are a } \\
\text { short-term bridging service from hospital or } \\
\text { corrections to a primary care provider. Both ACT } \\
\text { and AOT attempt to locate and help clients who } \\
\text { may be at risk and prevent issues before they } \\
\text { happen. } \\
\text { Hours of Operation: 0700-1815 \& 1600-0345, } 7 \\
\text { days/week (Car } 87 \text { ); 0700-1615, } 7 \text { days/week } \\
\text { (ACT); 0700-2300, } 7 \text { days/week (AOT) } \\
\text { Assigned/Volunteer: Assigned | Rotation: } 5 \\
\text { years (Car 87) } \\
\text { Response: Requested by frontline (Car } 87 \text { ) | } \\
\text { Hospital Wait Time: } 2-3 \text { hrs }\end{array}$ \\
\hline
\end{tabular}




\begin{tabular}{|c|c|}
\hline Victoria & $\begin{array}{l}\text { The Greater Victoria Region has a variety of } \\
\text { integrated units comprised of officers from this } \\
\text { region }{ }^{5} \text {. The Integrated Mobile Crisis Response } \\
\text { Team (IMCRT) is comprised of nurses, } \\
\text { counsellors, child and youth mental health } \\
\text { clinicians, and two police officers - one from } \\
\text { Saanich and the other from Victoria. Officers } \\
\text { from Oak Bay and Central Saanich occasionally } \\
\text { fill in. In addition to the crisis response, Victoria } \\
\text { also has four Assertive Community Treatment } \\
\text { Teams (ACT), with three officers embedded } \\
\text { within, that can assist in finding long-term care, } \\
\text { housing, and more. } \\
\text { Hours of Operation: } 1200-2400,7 \text { days/week } \\
\text { (IMCRT); 0630-2000, } 5 \text { days/week (ACT) } \\
\text { Assigned/Volunteer: Either | Rotation: } 3 \text { years } \\
\text { (IMCRT) }\end{array}$ \\
\hline \multicolumn{2}{|l|}{ Manitoba } \\
\hline Winnipeg & - \\
\hline \multicolumn{2}{|l|}{ Nova Scotia } \\
\hline Annapolis Royal & - \\
\hline Ontario & \\
\hline
\end{tabular}




\begin{tabular}{|c|c|}
\hline Brantford & $\begin{array}{l}\text { Two Mobile Crisis Rapid Response Teams } \\
\text { (MCRRT) comprised of an officer/mental health } \\
\text { care specialist co-response, and one Mobile } \\
\text { Crisis Team (MCT) comprised of mental health } \\
\text { care specialists who respond at the request of } \\
\text { frontline. } \\
\text { Hours of Operation: 0900-1700 \& 1500-2300, } \\
\text { Monday-Friday (MCRRT), Unknown for MCT } \\
\text { Assigned/Volunteer: Assigned | Rotation: No } \\
\text { Response: First response if available (MCRRT); } \\
\text { requested by frontline (MCT) | Hospital Wait } \\
\text { Time: } 0-1 \text { hrs }\end{array}$ \\
\hline Brockville & $\begin{array}{l}\text { One officer is partnered with a mental health } \\
\text { worker who conduct proactive outreach work, } \\
\text { but can be requested by frontline at any time. } \\
\text { Hours of Operation: Fluid hours/days } \\
\text { Assigned/Volunteer: Either | Rotation: No } \\
\text { Response: Requested by frontline | Hospital } \\
\text { Wait Time: } 2 \text {-3hrs }\end{array}$ \\
\hline Chatham-Kent & $\begin{array}{l}\text { The HELP Team is comprised of officers who are } \\
\text { specially trained on mental health. One HELP } \\
\text { officer is paired with a psychiatric crisis nurse to } \\
\text { form the Mobile Crisis Team (MCT) for co- } \\
\text { response. } \\
\text { Hours of Operation: 0800-1600, Monday- } \\
\text { Friday (MCT) } \\
\text { Assigned/Volunteer: Assigned | Rotation: } 4 \\
\text { years (MCT) } \\
\text { Response: First response (HELP); requested by } \\
\text { frontline (MCT) | Hospital Wait Time: } 2 \text {-3hrs }\end{array}$ \\
\hline
\end{tabular}




\begin{tabular}{|c|c|}
\hline Durham Region & $\begin{array}{l}\text { Two co-response teams where an officer is } \\
\text { paired with a nurse. } \\
\text { Hours of Operation: } 0800-2100 \text {, Days unknown } \\
\text { Assigned/Volunteer: Either | Rotation: - } \\
\text { Response: Requested by frontline | Hospital } \\
\text { Wait Time: } 0-1 \mathrm{hrs}\end{array}$ \\
\hline LaSalle & - \\
\hline London & $\begin{array}{l}\text { Work with a mental health-based crisis team } \\
\text { through a formal agreement. Not a dedicated } \\
\text { pairing, but are on call and respond as needed. } \\
\text { Hours of Operation: } 24 \text { hours/day } \\
\text { Assigned/Volunteer: - | Rotation: - } \\
\text { Response: Requested by frontline | Hospital } \\
\text { Wait Time: } 2 \text {-3hrs }\end{array}$ \\
\hline Peel Region & $\begin{array}{l}\text { Crisis Outreach and Support Team (COAST) is a } \\
\text { co-response team comprised of a mental health } \\
\text { specialist and a police officer. Four officers are } \\
\text { on COAST, with two officers on duty. COAST also } \\
\text { connects individuals with community programs. } \\
\text { Hours of Operation: } 1100-2300,7 \text { days/week } \\
\text { (Mental health specialist works 1200-2130) } \\
\text { Assigned/Volunteer: Assigned / Rotation: No } \\
\text { Response: Requested by frontline | Hospital } \\
\text { Wait Time: } 4-5 \text { hrs }\end{array}$ \\
\hline St. Thomas & $\begin{array}{l}\text { Canadian Mental Health Association (CMHA) } \\
\text { worker co-responds with an officer. } \\
\text { Hours of Operation: 0700-1500, Days unknown } \\
\text { Assigned/Volunteer: -| Rotation: - } \\
\text { Response: Requested by frontline | Hospital } \\
\text { Wait Time: } 2 \text {-3hrs }\end{array}$ \\
\hline
\end{tabular}




\begin{tabular}{|c|c|}
\hline Windsor & $\begin{array}{l}\text { Two Community Outreach and Support Teams } \\
\text { (COAST) comprised of two officers and two crisis } \\
\text { workers who facilitate access to community } \\
\text { services and supports. COAST is a support team, } \\
\text { not a response team, and will only attend crisis } \\
\text { calls if the individual is a COAST client. } \\
\text { Hours of Operation: } 0800-1600 \text { \& } 1400-2000 \text {, } \\
\text { Monday-Friday } \\
\text { Assigned/Volunteer: Assigned | Rotation: } 3 \\
\text { years } \\
\text { Response: Requested by frontline if individual is } \\
\text { a COAST client | Hospital Wait Time: } 0-1 \text { hrs }\end{array}$ \\
\hline York Region & $\begin{array}{l}\text { One co-response with an officer and a crisis } \\
\text { worker, and two on call crisis workers who can } \\
\text { respond to calls when requested by frontline) } \\
\text { Hours of Operation: 1000-2200, } 7 \text { days/week } \\
\text { (Co-response); 0900-2400, } 7 \text { days/week (Crisis } \\
\text { workers) } \\
\text { Assigned/Volunteer: Either | Rotation: No } \\
\text { Response: Strives to be first response (Co- } \\
\text { response); requested by frontline (Crisis } \\
\text { workers) | Hospital Wait Time: } 2 \text {-3hrs }\end{array}$ \\
\hline \multicolumn{2}{|c|}{ Prince Edward Island } \\
\hline Charlottetown & - \\
\hline \multicolumn{2}{|l|}{ Quebec } \\
\hline Mont-Tremblant & - \\
\hline Saskatchewan & \\
\hline
\end{tabular}




\begin{tabular}{|c|c|}
\hline Regina & $\begin{array}{l}\text { Two Police and Crisis Teams (PACT) where an } \\
\text { officer is paired with a social worker. Four } \\
\text { officers are on PACT, and on each shift there are } \\
\text { two PACT-trained frontline officers to fill in or to } \\
\text { attend calls when PACT is not working. } \\
\text { Hours of Operation: } 0900-2100 \text {, Monday- } \\
\text { Friday (Social worker works 0900-2000) } \\
\text { Assigned/Volunteer: Volunteer | Rotation: } 5 \\
\text { years } \\
\text { Response: Requested by frontline | Hospital } \\
\text { Wait Time: } 4-5 \mathrm{hrs}\end{array}$ \\
\hline Saskatoon & $\begin{array}{l}\text { Two Police and Crisis Teams (PACT) where an } \\
\text { officer is paired with a mental health trained } \\
\text { social worker. } \\
\text { Hours of Operation: } 0700-1900 \text { \& 1300-0100, } \\
\text { Days unknown (Officers work 12-hour shifts; } \\
\text { social workers work 10-hour shifts) } \\
\text { Assigned/Volunteer: Either | Rotation: } 3-5 \\
\text { years } \\
\text { Response: First response | Hospital Wait } \\
\text { Time: } 2-3 \text { hrs }\end{array}$ \\
\hline Weyburn & - \\
\hline
\end{tabular}

\section{Footnotes}

1. The literature on mental health-related police interactions employs a variety of terms to refer to such interactions, with 'persons with mental illness' being among the most frequently used terms. As Frederick, O’Connor, and Koziarski (2018) note, among other issues, the use of this (and related) terms may lead to validity-related issues due to the uncertainty of whether the so-called 'person with mental illness' genuinely lives with a diagnosed or diagnosable mental illness, or if other issues may be at play. Within police data, mental health calls are most frequently coded as such by responding officers due to a perception or belief - on behalf of the officer, bystanders, etc. - that mental health-related issues may be present, as opposed to a 
certainty that they are present. This paper, therefore, employs the term 'persons with perceived mental illness' (PwPMI) to reflect this uncertainty. $\subseteq$

2. We mention 'effectiveness' with a word of caution. Various reviews have concluded that this body of research is still developing, and that there is insufficient evidence to establish whether these responses are truly 'evidence-based' (see Bird and Shemilt 2019; Shapiro et al. 2015; Taheri 2016; Watson, Compton, and Draine 2017; Dewa et al. 2018; Puntis et al. 2018). $\subseteq$ 